\title{
Ebola virus disease: an update for anesthesiologists and intensivists
}

\section{La maladie à virus Ebola: mise à jour pour les anesthésiologistes et intensivistes}

\author{
Duane J. Funk, MD • Anand Kumar, MD
}

Received: 11 September 2014/ Accepted: 17 October 2014/Published online: 6 November 2014

(C) The Author(s) 2014. This article is published with open access at Springerlink.com

\begin{abstract}
Purpose Ebola virus disease (EVD) is a viral hemorrhagic fever that is highly transmissible and all too often rapidly fatal. Recent outbreaks in West Africa reveal that this infection has the potential to be transmitted worldwide. Anesthesiologists and intensivists, due to their training in the management of the critically ill, may be called upon to assist in the management of these patients. The focus of this brief review is on the epidemiology, pathogenesis, and management of patients with EVD.

Source Review of the current literature.

Principal findings Ebola virus disease causes severe diarrhea, electrolyte disturbances and other major endorgan dysfunction. Early aggressive resuscitation may reduce the mortality of this disease. There is presently no available vaccine nor cure, with experimental therapies having yielded limited success. Personal protective equipment (PPE) is necessary for all patient contact, and
\end{abstract}

This article is accompanied by an editorial. Please see Can J Anesth 2015; 62: this issue.

Author contributions Duane J. Funk and Anand Kumar wrote the manuscript.

\section{J. Funk, MD}

Departments of Anesthesiology and Medicine, Section of Critical Care, Faculty of Medicine, University of Manitoba, 2nd Floor Harry Medovy House, 671 William Avenue,

Winnipeg, MB, Canada

\section{J. Funk, MD $(\varangle) \cdot$ A. Kumar, MD}

Sections of Infectious Disease and Critical Care, Department of Medicine, Faculty of Medicine, University of Manitoba, Winnipeg, MB, Canada

e-mail: funk@cc.umanitoba.ca enhanced PPE is required for all aerosol-generating medical procedures.

Conclusion Anesthesiologists and intensivists may be called upon to manage patients with EVD. It is important that these clinicians have an appreciation for the epidemiology and pathogenesis of this disease and for the proper utilization of PPE when treating these patients.

\section{Résumé}

Objectif La maladie à virus Ebola (MVE) est une fièvre virale hémorragique hautement transmissible et, beaucoup trop souvent, rapidement mortelle. Les récentes épidémies survenues en Afrique de l'Ouest démontrent que cette infection a le potentiel de se répandre dans le monde entier. Compte tenu de leur formation à la gestion de personnes gravement malades, les anesthésiologistes peuvent être appelés à aider à la prise en charge de ces patients. Cette courte synthèse fait le point sur l'épidémiologie, la pathogénie et la gestion des patients atteints de MVE.

Source Revue de la littérature actuelle.

Constatations principales La maladie à virus Ebola provoque une diarrhée sévère et des désordres électrolytiques. Une réanimation précoce, agressive peut réduire la mortalité liée à cette maladie. Il n'y a pas de traitement, mais des thérapies expérimentales ont été tentées avec un succès limité chez des patients infectés. Un équipement de protection individuel (EPI) est nécessaire pour tous les contacts avec le patient. Un EPI renforcé est requis pour toutes les procédures médicales générant un aérosol.

Conclusion Les anesthésiologistes et les intensivistes peuvent être appelés à prendre en charge les patients atteints de MVE. Il est important que les cliniciens connaissent l'épidémiologie et la pathogénie de cette 
maladie, ainsi que l'utilisation appropriée d'un EPI lorsqu'ils traitent ces patients.

In March 2014, the World Health Organization (WHO) was notified of an outbreak of Ebola virus disease (EVD), formerly known as Ebola hemorrhagic fever, in the forested areas of southeastern Guinea in West Africa. ${ }^{1}$ The disease subsequently spread to the capital, Conakry, and then to the neighbouring countries of Liberia, Nigeria, Sierra Leone, and Senegal. On August 8, 2014, the WHO declared the epidemic a Public Health Emergency of International Concern. ${ }^{2}$

Since the first reports of this most recent outbreak of EVD, it has spread rapidly and, at last report, had infected 9,936 people with 4,877 deaths. $^{3}$ Nevertheless, the trajectory of this epidemic suggests a strong likelihood that in excess of 1.4 million cases could occur. ${ }^{4}$ Thus far, the case fatality rate is $52 \%$, but it ranges from $42 \%$ in Sierra Leone to $66 \%$ in Guinea. A significant number of healthcare workers, including several physicians treating the patients in Africa, have also contracted the disease and have succumbed to it. The first reported case in Nigeria, which does not share a border with any of the other affected countries, signified the first time air travel was implicated in the spread of this disease. ${ }^{5}$ Since the report of this initial case, one patient with undiagnosed EVD who returned from Liberia to Dallas, Texas subsequently died of the disease. ${ }^{6}$ This was the first case of Ebola in North America that was not associated with returning healthcare workers. Subsequent to this case, two nurses in Texas caring for the Liberian patient contracted the disease, as did a nurse in Spain whom was caring for two priests who returned from Africa. ${ }^{7}$

With both infected and at-risk medical and infectious disease personnel being transported back to North America, it is entirely possible that a scenario of active EVD could occur in Canada. Anesthesiologists, due to their training in the management of the critically ill, may be called upon to assist in the management of these patients. The focus of this brief review is on the epidemiology, pathogenesis, and management of patients with EVD. Special attention is given to specific details regarding the personal protective equipment (PPE) that will be essential should care for these patients be required.

\section{Virology, epidemiology, and ecology}

The Ebola and Marburg viruses are members of the Filoviridae virus family. These viruses, known to cause hemorrhagic fever in humans, derive their name from their long filamentous structure.

Marburg virus, the first known Filovirus, was initially described in 1967 when imported infected primates from Uganda introduced the agent into a facility in Marburg, Germany that was manufacturing a polio vaccine. ${ }^{8}$ An infection outbreak characterized by fever, diarrhea, vomiting, massive bleeding from many different organs, shock and circulatory system collapse occurred in 31 lab workers and resulted in a $23 \%$ case fatality rate. In recent years, there have been rare imports of Marburg virus human infections to Western nations (but without further propagation).

Ebola virus was first described in an outbreak in the northwest area of the Democratic Republic of Congo (formerly known as Zaire) in central Africa in 1976. A second independent outbreak occurred in the same year near the town of N'zara in Sudan. All of the subsequent sporadic outbreaks (with the exception of the present one) have occurred in this region of central Africa. ${ }^{9}$ The Ebola virus is named after a small river in the area where the first recognized epidemic occurred. Ebola virus has five genetically distinct species named on the basis of the geographic region where they were discovered: Zaire ebolavirus, Sudan ebolavirus, Ivory Coast ebolavirus, Bundibugyo ebolavirus, and Reston ebolavirus. ${ }^{10,11}$ The Zaire and Sudan ebolaviruses have caused the majority of the outbreaks of EVD, while the Ivory Coast ebolavirus caused human disease (in 1994) in a worker performing an autopsy on an infected chimpanzee. ${ }^{12}$ Bundibugyo ebolavirus is the most recently described strain from an outbreak in Uganda in 2007. Reston ebolavirus was first discovered in 1989 in a facility in suburban Virginia housing cynomolgus monkeys imported from the Philippines that were being used to test cosmetics. ${ }^{13}$ Fortunately, Reston ebolavirus is non-pathogenic to humans.

The strain of the current outbreak is uncertain. One genetic analysis of the virus has suggested an altogether new viral species, termed Guinean Ebola $;{ }^{14}$ however, other authorities consider it a sub-strain to Zaire ebolavirus (personal communication, Gary Kobinger, Chief, Special Pathogens Branch, National Microbiology Laboratory, Public Health Agency of Canada, Winnipeg, MB).

The Ebola virus is an enveloped non-segmented ribonucleic acid (RNA) virus (Fig. 1) with a uniform diameter but a wide variation in length. ${ }^{15}$ The viral genome encodes several proteins, including the replication machinery of the virus. A soluble glycoprotein encoded by the viral genome and secreted by infected cells is thought to prevent the cytopathic effects of the host immune system on the infected cells. ${ }^{16}$ 

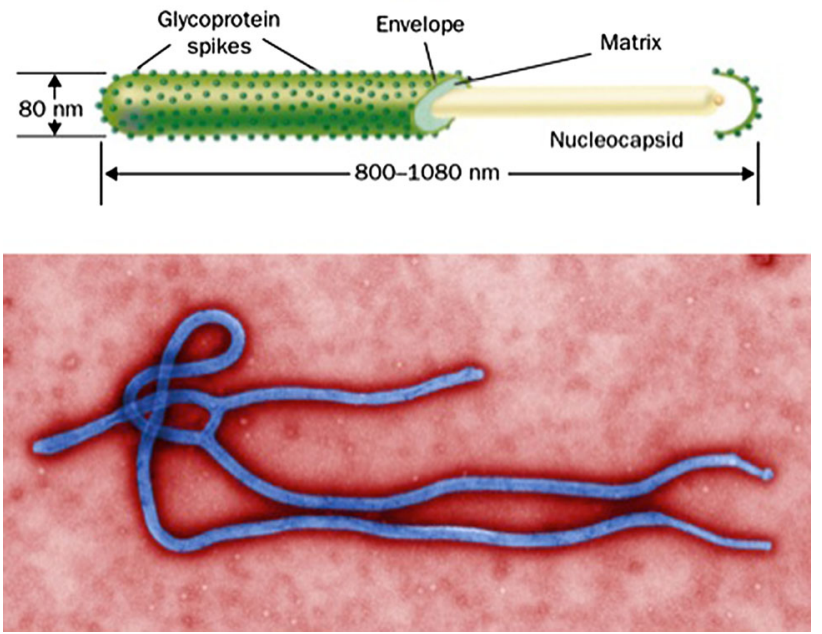

Fig. 1 Ebola virus structure and electron micrograph. Reproduced with permission from: Mahanty S, Bray M. Pathogenesis of filoviral haemorrhagic fevers. Lancet Infect Dis 2004; 4: 487-98 ${ }^{10}$

Ebola virus disease is a classic zoonotic disease with persistence of the virus in a reservoir species in endemic areas. ${ }^{17}$ Despite great effort during epidemics, the natural reservoir or an arthropod vector for Ebola has never been conclusively proven. Rodents and bats, however, have long been suspected as being a reservoir for the virus. The strongest evidence to date implicates fruit and insectivorous bats as hosts for the virus. ${ }^{18-20}$ Although human infection can occur as a consequence of contact with the carcasses of infected non-human primates (hunted as a food source), the extremely high mortality in these animals strongly argues against them as a reservoir. ${ }^{21}$

The virulence of the different Ebola viruses varies between strains. Zaire ebolavirus (suspected, though not yet confirmed, in this recent outbreak) has the highest case fatality rate of $60-90 \%$, followed by Sudan ebolavirus at $40-60 \%$. It is difficult to determine if these rates would be seen in the developed world with better access to medical care. The provision of supportive care to these patients would likely lessen mortality, particularly when comparing the $22 \%$ case fatality rate seen in the Marburg virus outbreak in Germany with the $88-90 \%$ mortality seen in the two major African outbreaks. ${ }^{22}$

\section{Pathogenesis}

Research on the pathogenesis of EVD in humans is limited due to the inaccessibility of the regions where outbreaks occur. Animal studies of the disease have focused on primate models.

Ebola virus appears to enter the host through mucosal surfaces or breaks in the skin, indicating the necessity of
PPE for healthcare workers. ${ }^{17}$ Infectious viral particles have been shown in blood, saliva, vomit, feces, urine, sweat, nasal secretions, and even semen and genital secretions. $^{23}$ Once Ebola virus enters a human population, its spread from person to person requires direct contact with bodily fluids. Despite the fact that some aerosolized Filoviruses (Reston ebolavirus) can spread between non-human primates via the respiratory route, there is no evidence that this occurs between humans, which suggests that the virus is not sufficiently aerosolized. ${ }^{24}$ Despite this fact, anesthesiologists asked to perform tracheal intubation on these patients or healthcare providers who are present during aerosol-generating medical procedures (AGMP) should take extra precautions beyond standard PPE (see below).

After entering the body, the Ebola virus initially infects the dendritic cells and macrophages (Fig. 2). These mobile cells carry the virus to regional lymph nodes where further replication occurs. ${ }^{10}$ From here, the virus is able to travel via the blood stream and lymphatic channels to the entire body. During infection, lymphocytes are not directly infected but undergo high rates of apoptosis. The resulting lymphopenia leads to a further weakening of the immune response and allows for unfettered viral replication. ${ }^{25}$ Ebola virus is distinct from other viruses in that it appears to have broad tissue tropism, i.e., it can infect virtually any cell type in the body. ${ }^{17}$ The glycoproteins released by infected cells act as a decoy to the host's immune system, soaking up antibodies and interfering with humoral responses. ${ }^{26}$ The soluble glycoprotein also causes direct cytotoxic effects, but the mechanism of this function has not been elucidated.

The vascular endothelium is thought to play a key role in the pathophysiology of the disease. ${ }^{27}$ Capillary leak caused by an associated systemic inflammatory response syndrome (SIRS) results in depletion of intravascular volume. Virally infected macrophages begin to express tissue factor on their cell surface that then leads to activation of the coagulation cascade and a consumptive coagulopathy, i.e., disseminated intravascular coagulation (DIC) ensues. Direct viral infection of hepatocytes results in hepatocellular necrosis and a further reduction in levels of coagulation factors.

Despite its previous name (Ebola hemorrhagic fever) and descriptions in the lay press of the disease "liquefying" its victims, the hemorrhage related to Ebola is usually a late manifestation of the disease and is predominantly gastrointestinal in nature, although cutaneous and conjunctival hemorrhage may be seen. ${ }^{28}$

Interestingly, patients infected with Ebola virus have been shown to increase production of pro-inflammatory cytokines, including tumor necrosis factor- $\alpha$, similar to the response found with SIRS in septic shock. ${ }^{29}$ Ebola virus 


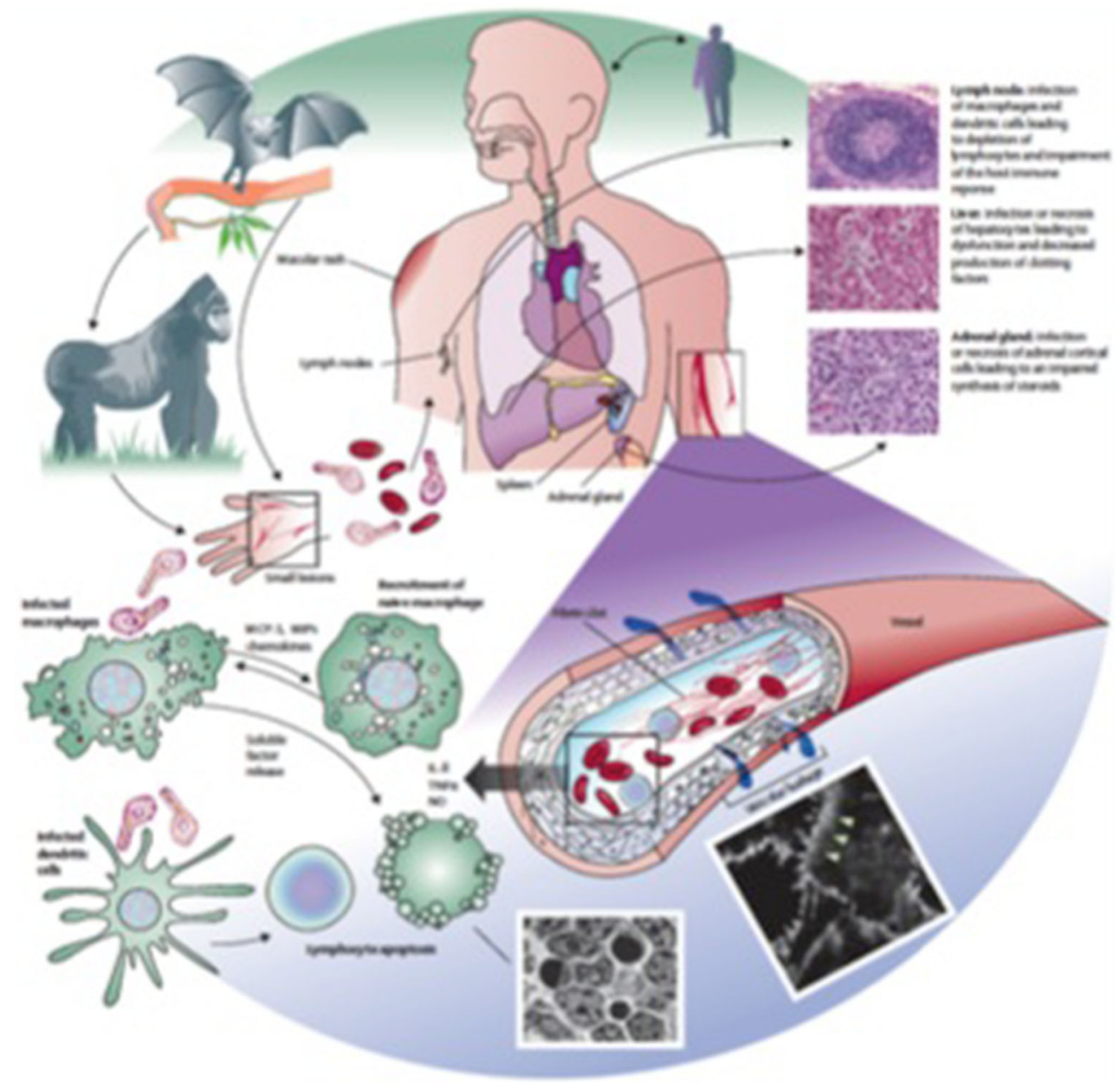

Fig. 2 Ebola virus pathogenesis: Ebola virus spreads from the initial infection site to the regional lymph nodes, liver, and spleen. Despite not being directly infected, lymphopenia is a common feature of the disease, likely due to apoptosis. Factors released from infected cells also contribute to capillary leakage as demonstrated here in cultures of endothelial cells (white arrowheads). The systemic virus spread leads to hypovolemia, shock, disseminated intravascular coagulation, and finally multi system organ failure and death. IL $=$ interleukin. MCP-1 = monocyte chemoattractant protein- 1 . MIPs = macrophage inflammatory proteins. $\mathrm{NO}=$ nitric oxide. $\mathrm{TNF} \alpha=$ tumour necrosis factor $\alpha$. Reproduced with permission from: Feldmann H, Geisbert $T W$. Ebola haemorrhagic fever. Lancet 2011; 377: 849-62 ${ }^{17}$ infection is also associated with increased blood levels of nitric oxide (NO), and this has been correlated with increased mortality. ${ }^{30}$ In addition to being an important mediator of hypotension, NO has been associated with lymphocyte apoptosis and loss of vascular integrity, which may further contribute to the hypovolemic shock seen in advanced stages of the disease.

\section{Clinical presentation}

The incubation period of EVD has been reported as two to 21 days. ${ }^{17,28,31,32}$ This wide range in incubation period may be due, in part, to the lack of reliable information regarding onset of symptoms in outbreak regions. The most reliable information on the incubation period for EVD comes from situations where a well-defined event has occurred, such as a laboratory or nosocomial exposure. The average incubation period in most of these cases appears to be four to ten days.

The different strains of Ebola virus appear to have somewhat variable distribution of their typical clinical features. In general, EVD patients typically present acutely with non-specific symptoms such as cough, rhinorrhea, chills, headache, myalgia, anorexia, nausea, vomiting, and diarrhea. Fever is ubiquitous and contributed to the earlier term for the disease, Ebola hemorrhagic fever. Temperatures as high as $39-40^{\circ} \mathrm{C}$ are common. The nonspecific initial presentation of EVD leads to a wide differential diagnosis, including malaria, typhoid, and other viral hemorrhagic fevers (including Lassa fever) that occur in the same regions. Unfortunately, by this time, 
previously unknown person-to-person transmission is a major concern.

The subsequent signs and symptoms of the disease are a manifestation of multisystem organ involvement of the virus. Prostration, increasing generalized edema, and severe abdominal pain are common. Neurologic signs and symptoms include severe headache, confusion, and decreased level of consciousness, which can be precursors to seizures and coma. These findings are typically preterminal events. As the disease progresses, worsening of gastrointestinal symptoms, specifically profound diarrhea and or vomiting, occur. This can lead to the development of hypovolemic shock and early death. Cough, chest pain, and shortness of breath may also occur, but overt respiratory failure, as is often seen in bacterial sepsis, is not a common feature of EVD. It is unclear whether this is due to a significant lack of direct involvement in the respiratory system or due to the fact that patients in outbreak areas usually succumb to their disease prior to the occurrence of respiratory failure.

The "hemorrhage" of this viral hemorrhagic fever is a late manifestation of the disease, and despite it being prominently featured in the naming of this disease, it occurs in only a minority of patients. Massive bleeding is typically isolated to the gastrointestinal tract; however, there are also numerous descriptions of conjunctival hemorrhage, petechiae, purpura, and oozing from venipuncture sites, typical of DIC.

There have been few reports with respect to typical laboratory and hemodynamic findings of the disease due to the austere environment where the disease typically develops. In the most recent epidemic, Fowler et al. describe the lack of ability to measure temperature, blood pressure, and oxygenation, let alone basic laboratory parameters. $^{28}$

Nonetheless, when available, laboratory testing shows a variety of abnormalities. Hemoglobin levels are typically normal or even elevated in early EVD due to dehydration. Significant leukopenia with marked lymphopenia and neutrophilia is common. Thrombocytopenia due to consumptive coagulopathy and reduced production is also a typical feature of the disease and frequently meets the criteria for DIC with platelet counts in the range of 50-100,000 $\mu \mathrm{L}^{-1} \cdot{ }^{17,32,33}$ Several reports have also described elevations in partial thromboplastin time and international normalized ratio.

Elevations of hepatocellular enzymes (two to three times normal), specifically aspartate and alanine aminotransferase (AST and ALT), can be seen with greater elevations being associated with increased risk of mortality. ${ }^{32,34}$ This elevation, however, is rarely to the extent seen in primary viral hepatitis infections and is almost always AST dominant, suggesting an ischemic/ hypoperfusion etiology. Pancreatic enzymes may also be elevated.

The most significant laboratory abnormalities relate to hypoperfusion and the consequences of the severe diarrhea these patients develop. A mixed metabolic acidosis (normal and increased anion gap) develops from the diarrhea, and lactate levels are elevated due to hypoperfusion. Hypokalemia, due to the diarrhea, is profound and serum levels less than $2 \mathrm{mEq} \cdot \mathrm{L}^{-1}$ have been described. ${ }^{28}$ This can lead to serious cardiac arrhythmias and death in a subset of patients. Acute kidney injury due to hypoperfusion is also frequently present.

Patients with fatal disease die typically during days six to16, usually of hypovolemic shock and multi-system organ failure. In non-fatal cases, patients have fever for several days and typically begin seeing clinical improvement during days six to 11. During the Congo outbreak in 1995, patients who survived to day 14 had a greater than $75 \%$ chance of survival. ${ }^{35}$

\section{Diagnosis}

At present, the gold standard for clinical diagnosis of EVD is real-time polymerase chain reaction (RT-PCR). Antigen detection with an enzyme-linked immunosorbent assay is also used. The RT-PCR testing of patient samples in the endemic West African areas is being performed in the field and, ironically, is sometimes the only laboratory testing available for patients. $^{28}$

\section{Management}

Prior to any possible hospital encounter with EVD, each facility should have a plan in place that specifically covers where these patients will be cared for, who will be caring for them (from both a physician and a nursing perspective), and detailed protocols for PPE utilization. The necessity for advanced planning and practice by facilities and clinicians that may be caring for these patients cannot be stressed enough. It is extremely important to have a high degree of familiarity with the required care procedures in order to lessen the chances of infecting healthcare workers.

The World Health Organization, the United States Centers for Disease Control and Prevention, and the Public Health Agency of Canada have each published Ebola clinical care guidelines for healthcare workers which are available from their respective websites: (http://www. who.int/csr/disease/ebola/protective-measures-staff/en/ http:// www.cdc.gov/vhf/ebola/hcp/index.html, and http://www. phac-aspc.gc.ca/id-mi/vhf-fvh/ebola-ipc-pci-eng.php). The focus of the remainder of this article is on the clinical care 


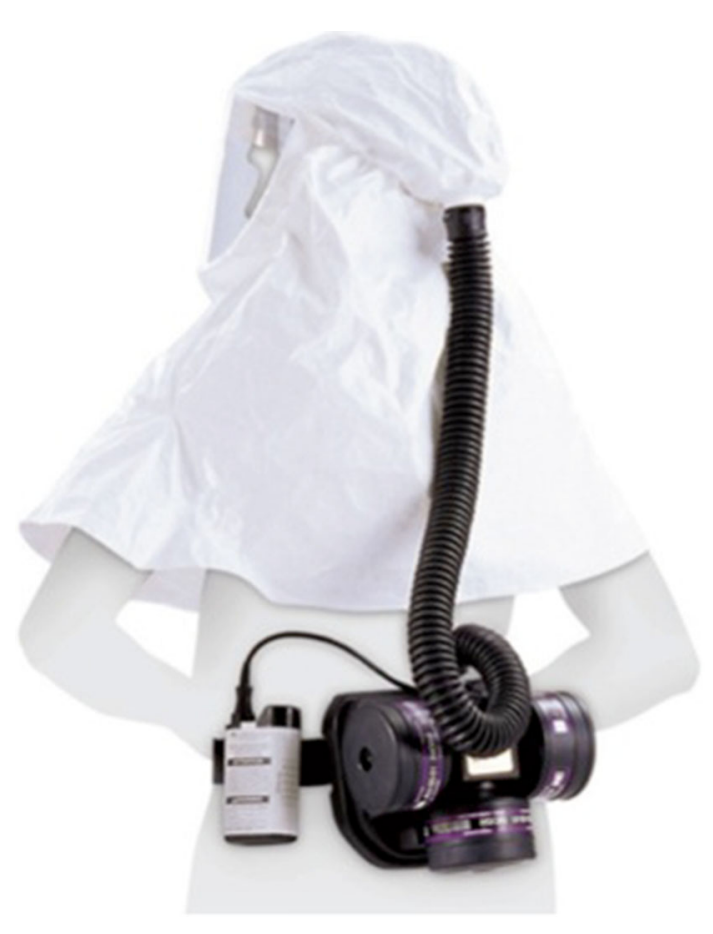

Fig. 3 Powered air purifying respirator (PAPR) hood

of EVD patients, with special attention devoted to those areas where anesthesiologists may be involved with these patients (resuscitation and airway management).

Patient care and personal protection

Patients with EVD should be cared for in a single-patient room that is physically separated from other patient care areas. The patient's room should have a private anteroom for donning and removing the PPE as well as washing facilities. Ideally, the patient room should have negative pressure isolation, particularly if clinicians will be performing aerosol-generating medical procedures (AGMP). The ability to dispose of patient's body fluids inside the room should also be present. Suction, monitors, medical gas connections, and adequate space for life support equipment should also be present. In most hospitals, the intensive care unit is the most practical place for the care of EVD patients. Ideally, as few people as possible should be involved in the direct care of these patients.

It is important to have a thorough understanding of the current guidelines that outline the minimally acceptable standards for patient isolation and protection of healthcare staff (see http://www.phac-aspc.gc.ca/id-mi/vhf-fvh/ebolaipc-pci-eng.php and http://www.sccm.org/SiteCollection Documents/Disaster-Response-Ebola-Hospital-Checklist.pdf). Healthcare staff must wear disposable water-resistant coveralls (preferably with a hood), a waterproof apron or impermeable gown, an N95 mask, a disposable full-face shield, two sets of gloves, and impermeable foot and leg coverings. While current guidelines suggest the adequacy of a well-fitted N95 mask, we recommend that clinicians use a powered air purifier respirator suit (PAPR) when performing AGMP such as airway suctioning or intubation. This adds an additional layer of protection and provides high-efficiency particulate air (HEPA) filtering as well as fresh air to the clinician (Fig. 3). There are logistical and practical issues with the use of PAPR suits that may limit their use (see below).

Invasive monitoring

The decision to institute invasive monitoring should be carefully considered with respect to the benefit to the patient and the risk to the healthcare staff. While significant bruising and ecchymosis may result from repeated noninvasive blood pressure measurements, the institution of invasive arterial blood pressure monitoring places healthcare workers at risk for contamination in the case of a circuit disconnection or leak. If arterial monitoring is implemented, access should be avoided through the femoral area due to the frequency of soiling in the region.

Similarly, centrally or peripherally inserted central catheters should not be placed for the purpose of central venous pressure monitoring alone, as this has been shown to be of limited clinical utility, and its validity as a marker of preload has been questioned. ${ }^{36,37}$ All of the following indications would be appropriate for placement of a central venous cannula: to ensure low-risk access to blood samples, to deliver electrolyte replacement, to administer vasoactive medications, or to utilize central venous oxygenation saturation as a marker for cardiac output. ${ }^{38}$ If the decision is made to place a central cannula, experienced clinicians should conduct the procedure, ensuring to employ ultrasound guidance. $^{39,40}$ Consideration should be given to the use of non-suture securing devices to minimize the number of skin punctures and the potential for needle stick injury. Needle-less systems, whether used for peripheral or central venous access, should be used at all times.

\section{Clinical treatment}

The mainstay of the treatment of EVD is aggressive resuscitation with intravenous fluids and correction of electrolyte abnormalities. Adequate intravenous access is necessary for fluid resuscitation of these patients as they will likely be hypovolemic from significant diarrhea. Where possible, it is important to stay ahead of volume 
losses rather than merely reacting to clinical signs of hypovolemia.

Ringer's lactate (RL) is the preferred solution for a number of reasons. When compared with resuscitation with normal saline, RL causes less acidosis, kidney injury, and bleeding. ${ }^{41-43}$ The hyperchloremia that typically ensues after normal saline administration has also been associated with increased mortality. ${ }^{44}$ The additional acidosis that results from normal saline administration in these patients may be particularly problematic, as the metabolic acidosis caused by the diarrhea may render patients unable to maintain an adequate minute ventilation to maintain a normal $\mathrm{pH}$, especially in the setting of hypokalemia which may weaken respiratory muscles.

Based on extrapolated data from patients with Dengue fever and those with septic shock, colloid solutions (including synthetic starches and human albumin) do not have a role in the resuscitation of patients with EVD, as they have shown no evidence of efficacy and have the potential for adverse renal outcomes. ${ }^{45-48}$

As patients with Ebola virus may progress to DIC, the need for transfusion of coagulation factors may become necessary. Transfusion of coagulation factors and platelets should be reserved for those patients who are clinically bleeding, as there is no evidence of benefit for prophylactic transfusions. ${ }^{49}$

As mentioned previously, severe electrolyte abnormalities, most notably hypokalemia, are likely to occur in patients with EVD. Enteral replacement is the preferred method, but in patients with severe nausea and vomiting, intravenous replacement may be required. If this is the case, it should be done via the central route.

\section{Airway management}

While primary respiratory failure is not a usual feature of EVD, secondary causes might occur, including shock, acute lung injury, fluid overload, respiratory muscle fatigue (from electrolyte disturbances and respiratory acidosis), and transfusion-related acute lung injury. In these situations, anesthesiologists may become involved, as only the most skilled practitioners in this area should perform any airway manipulation.

Noninvasive positive pressure (NIPPV) ventilation is relatively contraindicated due to the high incidence of vomiting and hematemesis and the risk of aspiration in these patients. Also, NIPPV may result in prolonged aerosolization of fluids containing the virus, placing caregivers at prolonged risk for contracting Ebola virus infection.

Ideally, endotracheal intubation should be performed only in an elective or semi-elective fashion. This minimizes the chances of error that might occur when donning PPE for the urgent care of a deteriorating patient.

The addition of a PAPR suit should be strongly considered when performing endotracheal intubation on these patients. Although a well-fitted N95 mask and face shield is minimally adequate according to current guidelines, a PAPR unit may provide better protection from aerosolized virus-containing fluids than an N95 mask and it is also more comfortable.

When compared with an N95 mask, PAPR suits have enhanced filtration ability due to their built-in HEPA filter. Also, positive airflow from inside to outside the PAPR suit forces contaminated air away from the user. Further, unlike N95 masks, no special fit testing is required for PAPR suits.

The advantages of PAPR suits must be balanced against several potential disadvantages. First, not every institution will have access to PAPR suits, as they are not common equipment in the healthcare setting. Second, the PAPR unit requires testing before use in order to ensure proper functioning. This necessarily delays donning the suit and may be disadvantageous when clinicians must respond in a timely fashion to a critically ill patient with EVD. Finally, removing PAPR suits is more complicated than removing the recommended basic PPE. As a result, the clinician could potentially be contaminated during the removal of the suit.

The risks of using these suits must be balanced against the benefits. Several important points must be emphasized regarding this subject. First, clinicians must practice putting on and removing the suits prior to actual contact with an EVD patient. This should be done in cooperation with the department responsible for infection prevention and control, and a checklist protocol should be developed to ensure that it is done precisely and with exacting standards each and every time. The procedures for putting on and removing PPE are outlined in the Appendix. Regular practice sessions should occur to keep clinicians familiarized with the proper PAPR suit procedures. Second, as the WHO or the Centers for Disease Control and Prevention do not recommend PAPR suits as part of PPE, clinicians may not want to utilize them as they are cumbersome to remove. It is the removal of PPE that has caused the majority of cases of EVD transmission to healthcare workers, and PAPR suits add another layer of complexity to PPE removal.

Even though respiratory transmission of EVD has not been confirmed, rapid sequence intubation with the use of neuromuscular blocking agents is highly recommended to reduce the risk of coughing with aerosolization. Further, patients requiring tracheal intubation may have 
hematemesis or may vomit, increasing the risk of viral transmission to healthcare workers. To lessen the risk of transmission during intubation, the minimum number of required personnel should be in attendance in the room.

Specific therapy and vaccination

At present, no specific therapy or vaccine is effective for EVD. Typical antivirals, such as ribavirin, have not shown efficacy when given to infected humans. Similarly, no other currently available agents have been successful in animal models of EVD. ${ }^{50,51}$ There have been numerous experimental therapies in non-human primates with variable success. These include recombinant human activated protein C, RNA interference with oligonucleotides, and human convalescent serum. ${ }^{52}$

During this most recent outbreak, several healthcare workers were treated with an experimental drug, ZMapp (Mapp Biopharmaceutical, San Diego, CA, USA). This drug is a combination of three monoclonal antibodies with known neutralizing activity against EVD that has been produced in genetically modified tobacco plants. This approach yielded $100 \%$ protection in a primate model within five days of infection challenge. ${ }^{53}$ Two American patients who were administered this drug survived, but both a Liberian physician and a Spanish clergyman who were given the drug during the same outbreak succumbed to the disease. At present, ZMapp is considered experimental therapy, and the current supply of the drug will limit its large-scale use for the immediate future.

Recently, the WHO has supported the use of convalescent blood, serum, or hyperimmune globulin from survivors of Ebola virus infection as an experimental therapy. Although there is no proven utility with respect to EVD, historical data with other severe viral infections and limited human studies with EVD suggest possible efficacy. ${ }^{54,55}$

Post-exposure prophylaxis with a recombinant vaccine, based on the vesicular stomatitis virus, has shown remarkable usefulness in non-human primates, ${ }^{56,57}$ but human trials have only just begun and have not reported results. Previously, the utility of developing an Ebola vaccine had been disputed due to the disease's rarity and potential cost of development. Nevertheless, the increased frequency of outbreaks, case reports of "imported" viral hemorrhagic fevers in travellers, and the potential misuse of the virus as a bioterror agent have altered this viewpoint. At present, several other candidate vaccines have been developed but have not been tested in humans due to safety and ethical concerns. ${ }^{58-60}$ Their development has been accelerated in view of the severity of the current epidemic.

\section{Summary}

Ebola virus disease is a highly transmissible highly fatal viral hemorrhagic fever. Anesthesiologists, with their training in the management of the critically ill, may be called upon to assist in the management of these patients, either for intubation, or to assist with resuscitation. As there is no approved therapy for EVD, the meticulous use of PPE is required for all patient contact.

The chance of an EVD patient presenting to any given hospital is unquantifiable; therefore, it is essential that clinicians have an understanding of this disease. Hospitals should have protocols in place to deal with patients with this disease or other highly transmissible and fatal infectious diseases.

Conflicts of interest None declared.

Open Access This article is distributed under the terms of the Creative Commons Attribution Noncommercial License which permits any noncommercial use, distribution, and reproduction in any medium, provided the original author(s) and the source are credited.

\section{Appendix: Putting on and removing personal protective equipment (PPE)}

Equipment required

- Disposable (or non-disposable to be destroyed) scrubs

- Fluid-resistant coveralls with attached hood

- Impermeable gown

- Long gloves with secure cuff $\times 2$

- Fluid-resistant shoe/leg coverings

- N95 respirator

- Procedure/Surgical mask

- Full-face shield

- Closed toe and heel shoes (dedicated to unit)

- Basin for Oxivir TB RTU solution $\times 3$ (2 in anteroom, 1 in patient room)

- Mayo stand to support basin with solution in patient room

- Tape for marking anteroom floor (identify space for contaminated staff and assist staff)

- Walk-off mat for disinfectant

\section{Donning PPE}

- On arrival to unit, change into disposable scrubs and dedicated shoes in change room

- Remove jewellery, lanyards, and so on

- Securely tie hair back if required 
Outside patient room (for entry)

1. Perform hand hygiene $(\mathrm{HH})$. Alcohol-based hand rub (ABHR) is acceptable unless visible soiling is present; soap and water required if soiling present

2. Put on $1^{\text {st }}$ set of gloves

3. a. Put on coveralls; close zipper; pull hood securely onto head

b. Ensure $1^{\text {st }}$ set of gloves is under sleeves of coveralls

4. Put on shoe/leg coverings

5. a. Put on impermeable gown

b. Ensure gown covers backside. If not covered completely, first don a gown as a housecoat, and then put on the second gown as usual.

6. Put on N95 respirator/mask over hood

7. Put on full-face shield over hood

8. Put on $2^{\text {nd }}$ set of gloves over impermeable gown; ensure cuffs of gloves are secure over cuff of gown

9. Trained monitor to confirm appropriate PPE application/fitting before individual enters anteroom

\section{Removing PPE}

$2^{\text {nd }}$ person (assistant) PPE: disposable (or non-disposable to be destroyed) scrubs; impermeable gown; gloves $\times 1$; procedure/surgical mask; full-face shield

- Assistant to immerse gloves and to rub together carefully in Oxivir TB RTU solution after each contact with the primary individual

- Assistant can remove their PPE alone; assistance from primary with untying gown may be needed

- If assistant to aide multiple individuals (i.e., one after another), new PPE required between each person being assisted

\section{Exiting patient room}

Only 1 person at a time shall exit the patient room. PPE must be removed completely, and the anteroom must be exited before the next person enters the anteroom.

1. In patient room, immerse gloved hands into basin and carefully rub together; wipe door handle with Oxivir TB wipe; allow 1 minute drying time before exiting the patient room

2. Enter the anteroom staying in the half of the room closest to the patient room (delineated by tape); ensure contact with walk-off mat

a. Immerse gloved hands into basin and carefully rub together in Oxivir TB RTU solution
3. After door closes, $2^{\text {nd }}$ person (assistant) to enter the anteroom staying on the half closest to hallway

4. Remove outer set of gloves using glove-to-glove skin-to-skin technique

5. Immerse gloved hands into basin and carefully rub together in Oxivir TB RTU solution

6. Remove gown (with assistance if needed)

7. Immerse gloved hands into basin and carefully rub together in Oxivir TB RTU solution

8. Remove shoe/leg coverings (with assistance if needed)

9. Immerse gloved hands and carefully rub together in Oxivir TB RTU solution

10. Remove face shield (by strap behind head)

11. Immerse gloved hands and carefully rub together in Oxivir TB RTU solution

12. Remove N95 respirator/mask by straps behind head and with eyes closed

13. Immerse gloved hands and carefully rub together in Oxivir TB RTU solution

14. Remove coveralls with assistance

a. Assistant to unzip coveralls carefully to lower abdomen by pulling front area of coveralls downwards, tilting head upwards, and continuing to unzip

b. Using outside of hood, assistant to uncover hood carefully from head

c. Assistant to peel suit downwards to expose shoulders, allowing hood to be further away from neck d. Using outside of sleeves, assistant to remove one sleeve at a time. Carefully roll coveralls downward in a manner avoiding contamination of disposable scrubs. Remove coveralls

15. Immerse gloved hands and carefully rub together in Oxivir TB RTU solution

16. Remove inner set of gloves

17. Perform HH (ABHR acceptable unless visible soiling present; if present, soap and water required)

18. Once $2^{\text {nd }}$ person has removed PPE, exit anteroom. Primary may exit at the same time

Wash gloves/perform hand hygiene whenever possible hand contamination has taken place, at any point during PPE removal.

\section{Assistant PPE removal}

1. Remove gloves using glove-to-glove skin-to-skin technique

2. Remove gown

3. Untie neck, then waist

4. Hook fingers under opposite cuff; pull over hand 
5. Use gown-covered hand to pull gown over other hand

6. Pull gown off without touching outside of gown

7. Roll up inside out and carefully dispose

8. Perform HH (ABHR acceptable unless visible soiling present; if present, soap and water required)

9. Remove face shield (by strap behind head)

10. Remove mask by loops/straps behind ears/head. Do not touch front of mask

11. Perform HH (ABHR acceptable unless visible soiling present; if present, soap and water required)

Perform hand hygiene whenever possible hand contamination has taken place, at any point during PPE removal.

Exiting patient room checklist (primary)

Only 1 person at a time shall exit the patient room. PPE must be removed completely and anteroom must be exited before next person enters the anteroom.

1. In patient room, immerse gloved hands into basin and carefully rub together

2. Wipe door handle with Oxivir TB wipe; allow 1 minute dry time before exiting the patient room

3. Enter anteroom staying in the half of the room closest to the patient room (delineated by tape); ensure contact with walk-off mat

4. Immerse gloved hands into basin and carefully rub together

5. After door closes, $2^{\text {nd }}$ person to enter staying in the half closest to hallway

6. Remove outer set of gloves using glove-to-glove, skin-to-skin technique

7. Remove gown (with assistance if needed)

8. Immerse gloved hands into basin and carefully rub together

9. Remove shoe/leg coverings (with assistance if needed)

10. Immerse gloved hands and carefully rub together in Oxivir TB RTU solution

11. Remove face shield (by strap behind head)

12. Immerse gloved hands and carefully rub together in Oxivir TB RTU solution

13. Remove N95 respirator/mask by straps behind head and with eyes closed

14. Immerse gloved hands and carefully rub together in Oxivir TB RTU solution

15. Remove coveralls with assistance

a. Assistant to unzip coveralls carefully to lower abdomen by pulling front area of coveralls downwards, tilting head upwards, and continuing to unzip b. Using outside of hood, assistant to uncover hood carefully from head

c. Assistant to peel suit downwards to expose shoulders, allowing hood to be further away from neck

d. Using outside of sleeves, assistant to remove one sleeve at a time. Carefully roll coveralls downward in a manner avoiding contamination of disposable scrubs. Remove coveralls

16. Immerse gloved hands and carefully rub together in Oxivir TB RTU solution

17. Remove inner set of gloves

18. Perform HH. ABHR acceptable unless visible soiling present; if present, soap and water required

19. Once $2^{\text {nd }}$ person has removed PPE, exit anteroom. Primary may exit at the same time

Wash gloves/perform $\mathrm{HH}$ whenever possible hand contamination has occurred, at any point during PPE removal.

Exiting patient room checklist (assistant)

Only 1 person at a time shall exit patient room. PPE must be removed completely and anteroom exited before the next person enters the anteroom.

1. Remove gloves using glove-to-glove skin-to-skin technique

2. Remove gown

3. Untie neck, then waist

4. Hook fingers under opposite cuff; pull over hand

5. Use gown-covered hand to pull gown over other hand

6. Pull gown off without touching outside of gown

7. Roll up inside out and carefully dispose

8. Perform HH (ABHR acceptable unless visible soiling present; if present, soap and water required)

9. Remove face shield (by strap behind head)

10. Remove mask by loops/straps behind ears/head. Do not touch front of mask

11. Perform HH (ABHR acceptable unless visible soiling present; if present, soap and water required)

Wash gloves/perform $\mathrm{HH}$ whenever possible hand contamination has occurred, at any point during PPE removal.

\section{References}

1. World Health Organization. Ebola Virus Disease in Guinea. Available from URL: http://www.who.int/csr/don/archive/ disease/ebola/en/ (accessed October 2014).

2. Briand S, Bertherat E, Cox P, et al. The international Ebola emergency. N Engl J Med 2014; 371: 1180-3. 
3. World Health Organization. Ebola Virus Disease Update - West Africa. Available from URL: http://www.who.int/csr/don/ archive/disease/ebola/en/ (accessed October 2014).

4. Meltzer MI, Atkins CY, Santibanez S, et al. Estimating the future number of cases in the ebola epidemic - liberia and sierra leone, 2014-2015. MMWR Surveill Summ 2014; 63: 1-14.

5. Chan M. Ebola virus disease in West Africa - no early end to the outbreak. N Engl J Med 2014; 371: 1183-5.

6. Centers for Disease Control. Cases of Ebola Diagnosed in the United States. Available from URL: http://www.cdc.gov/vhf/ ebola/outbreaks/2014-west-africa/united-states-imported-case.html (accessed October 2014).

7. New York Times. Ebola Infects Spanish Nurse, a First in West. Available from URL: http://www.nytimes.com/2014/10/07/ world/europe/spain-reports-first-case-of-ebola-contracted-outsidewest-africa.html?_r=0 (accessed October 2014).

8. Martini GA. Marburg agent disease: in man. Trans R Soc Trop Med Hyg 1969; 63: 295-302.

9. Johnson KM, Lange JV, Webb PA, Murphy FA. Isolation and partial characterisation of a new virus causing acute haemorrhagic fever in Zaire. Lancet 1977; 1: 569-71.

10. Mahanty S, Bray $M$. Pathogenesis of filoviral haemorrhagic fevers. Lancet Infect Dis 2004; 4: 487-98.

11. Towner JS, Sealy TK, Khristova ML, et al. Newly discovered ebola virus associated with hemorrhagic fever outbreak in Uganda. PLoS Pathog 2008; 4: e1000212.

12. Formenty $P$, Hatz C, Le Guenno B, Stoll A, Rogenmoser P, Widmer A. Human infection due to Ebola virus, subtype Cote d'Ivoire: clinical and biologic presentation. J Infect Dis 1999; 179(Suppl 1): S48-53.

13. Jahrling PB, Geisbert TW, Dalgard DW, et al. Preliminary report: isolation of Ebola virus from monkeys imported to USA. Lancet 1990; 335: 502-5.

14. Baize S, Pannetier D, Oestereich L, et al. Emergence of Zaire Ebola virus disease in Guinea. N Engl J Med 2014; 371: 1418-25.

15. Sanchez A, Geisbert TW, Feldmann H. Filoviridae: Marburg and Ebola viruses. In: Knipe DM, Howley PM, Griffin DE, editors. Fields Virology. Philadelphia: Lippincott Williams \& Wilkins; 2006. p. 1409-48.

16. Volchkov VE, Volchkova VA, Muhlberger E, et al. Recovery of infectious Ebola virus from complementary DNA: RNA editing of the GP gene and viral cytotoxicity. Science 2001; 291: 1965-9.

17. Feldmann H, Geisbert TW. Ebola haemorrhagic fever. Lancet 2011; 377: 849-62.

18. Leroy EM, Kumulungui B, Pourrut X, et al. Fruit bats as reservoirs of Ebola virus. Nature 2005; 438: 575-6.

19. Morvan JM, Deubel V, Gounon P, et al. Identification of Ebola virus sequences present as RNA or DNA in organs of terrestrial small mammals of the Central African Republic. Microbes Infect 1999; 1: 1193-201.

20. Swanepoel R, Leman PA, Burt FJ, et al. Experimental inoculation of plants and animals with Ebola virus. Emerg Infect Dis 1996; 2: 321-5.

21. Bermejo M, Rodriguez-Teijeiro JD, Illera G, Barroso A, Vila C, Walsh PD. Ebola outbreak killed 5000 gorillas. Science 2006; 314: 1564.

22. Changula K, Kajihara M, Mweene AS, Takada A. Ebola and Marburg virus diseases in Africa: increased risk of outbreaks in previously unaffected areas? Microbiol Immunol 2014; 58: 483-91.

23. Zaki SR, Shieh WJ, Greer PW, et al. A novel immunohistochemical assay for the detection of Ebola virus in skin: implications for diagnosis, spread, and surveillance of Ebola hemorrhagic fever. Commission de Lutte contre les Epidémies a Kikwit. J Infect Dis 1999; 179 Suppl 1: S36-47.
24. Dowell SF, Mukunu R, Ksiazek TG, Khan AS, Rollin PE, Peters $C J$. Transmission of Ebola hemorrhagic fever: a study of risk factors in family members, Kikwit, Democratic Republic of the Congo, 1995. Commission de Lutte contre les Epidémies a Kikwit. J Infect Dis 1999; 179(Suppl 1): S87-91.

25. Geisbert TW, Hensley LE, Gibb TR, Steele KE, Jaax NK, Jahrling $P B$. Apoptosis induced in vitro and in vivo during infection by Ebola and Marburg viruses. Lab Invest 2000; 80: 171-86.

26. Lee JE, Fusco ML, Hessell AJ, Oswald WB, Burton DR, Saphire $E O$. Structure of the Ebola virus glycoprotein bound to an antibody from a human survivor. Nature 2008; 454: 177-82.

27. Geisbert TW, Young HA, Jahrling PB, Davis KJ, Kagan E, Hensley $L E$. Mechanisms underlying coagulation abnormalities in ebola hemorrhagic fever: overexpression of tissue factor in primate monocytes/macrophages is a key event. J Infect Dis 2003; 188: 1618-29.

28. Fowler RA, Fletcher T, Fischer WA 2nd, et al. Caring for Critically ill patients with ebola virus disease: perspectives from West Africa. Am J Respir Crit Carer Med 2014; 190: 733-7.

29. Villinger F, Rollin PE, Brar SS, et al. Markedly elevated levels of interferon (IFN)-gamma, IFN-alpha, interleukin (IL)-2, IL-10, and tumor necrosis factor-alpha associated with fatal Ebola virus infection. J Infect Dis 1999; 179(Suppl 1): S188-91.

30. Sanchez A, Lukwiya M, Bausch D, et al. Analysis of human peripheral blood samples from fatal and nonfatal cases of Ebola (Sudan) hemorrhagic fever: cellular responses, virus load, and nitric oxide levels. J Virol 2004; 78: 10370-7.

31. Clark DV, Jahrling PB, Lawler JV. Clinical management of filovirus-infected patients. Viruses 2012; 4: 1668-86.

32. Kortepeter $M G$, Bausch DG, Bray $M$. Basic clinical and laboratory features of filoviral hemorrhagic fever. J Infect Dis 2011; 204(Suppl 3): S810-6.

33. Hunt BJ. Bleeding and coagulopathies in critical care. $\mathrm{N}$ Engl J Med 2014; 370: 847-59.

34. Rollin PE, Bausch DG, Sanchez A. Blood chemistry measurements and D-Dimer levels associated with fatal and nonfatal outcomes in humans infected with Sudan Ebola virus. J Infect Dis 2007; 196(Suppl 2): S364-71.

35. Sadek RF, Khan AS, Stevens G, Peters CJ, Ksiazek TG. Ebola hemorrhagic fever, Democratic Republic of the Congo, 1995: determinants of survival. J Infect Dis 1999; 179(Suppl 1): S24-7.

36. Marik PE, Cavallazzi R. Does the central venous pressure predict fluid responsiveness? An updated meta-analysis and a plea for some common sense. Crit Care Med 2013; 41: 1774-81.

37. Kumar A, Anel R, Bunnell E, et al. Pulmonary artery occlusion pressure and central venous pressure fail to predict ventricular filling volume, cardiac performance, or the response to volume infusion in normal subjects. Crit Care Med 2004; 32: 691-9.

38. Walley KR. Use of central venous oxygen saturation to guide therapy. Am J Respir Crit Care Med 2011; 184: 514-20.

39. Lamperti $M$, Bodenham AR, Pittiruti $M$, et al. International evidence-based recommendations on ultrasound-guided vascular access. Intensive Care Med 2012; 38: 1105-17.

40. Weiner MM, Geldard $P$, Mittnacht AJ. Ultrasound-guided vascular access: a comprehensive review. Journal of Cardiothoracic and Vascular Anesthesia 2013; 27: 345-60.

41. Kiraly LN, Differding JA, Enomoto TM, et al. Resuscitation with normal saline (NS) vs. lactated ringers (LR) modulates hypercoagulability and leads to increased blood loss in an uncontrolled hemorrhagic shock swine model. J Trauma 2006; 61: 57-64; discussion 64-5.

42. O'Malley CM, Frumento RJ, Hardy MA, et al. A randomized, double-blind comparison of lactated Ringer's solution and $0.9 \%$ $\mathrm{NaCl}$ during renal transplantation. Anesth Analg 2005; 100: 1518-24. 
43. Yunos NM, Bellomo R, Hegarty C, Story D, Ho L, Bailey M. Association between a chloride-liberal vs chloride-restrictive intravenous fluid administration strategy and kidney injury in critically ill adults. JAMA 2012; 308: 1566-72.

44. McCluskey SA, Karkouti K, Wijeysundera D, Minkovich L, Tait $G$, Beattie WS. Hyperchloremia after noncardiac surgery is independently associated with increased morbidity and mortality: a propensity-matched cohort study. Anesth Analg 2013; 117: 412-21.

45. Finfer $S$, Bellomo R, Boyce $N$, et al. A comparison of albumin and saline for fluid resuscitation in the intensive care unit. $\mathrm{N}$ Engl $\mathrm{J}$ Med 2004; 350: 2247-56.

46. Brunkhorst FM, Engel C, Bloos $F$, et al. Intensive insulin therapy and pentastarch resuscitation in severe sepsis. N Engl $\mathrm{J}$ Med 2008; 358: 125-39.

47. Myburgh JA, Finfer S, Bellomo R, et al. Hydroxyethyl Starch or saline for fluid resuscitation in intensive care. N Engl J Med 2012; 367: 1901-11.

48. Perner A, Haase N, Guttormsen AB, et al. Hydroxyethyl starch $130 / 0.42$ versus Ringer's acetate in severe sepsis. N Engl J Med 2012; 367: 124-34

49. Levi M, Schultz M, van der Poll T. Disseminated intravascular coagulation in infectious disease. Semin Thromb Hemost 2010; 36: 367-77.

50. Huggins $J W$. Prospects for treatment of viral hemorrhagic fevers with ribavirin, a broad-spectrum antiviral drug. Rev Infect Dis 1989; 11(Suppl 4): S750-61.

51. Ignatyev $G$, Steinkasserer A, Streltsova $M$, Atrasheuskaya A, Agafonov A, Lubitz W. Experimental study on the possibility of treatment of some hemorrhagic fevers. J Biotechnol 2000; 83: $67-76$.
52. Choi JH, Croyle MA. Emerging targets and novel approaches to Ebola virus prophylaxis and treatment. BioDrugs 2013; 27: 565-83.

53. Qiu X, Wong G, Audet J, et al. Reversion of advanced Ebola virus disease in nonhuman primates with ZMapp. Nature 2014; 514: 47-53.

54. Luke TC, Kilbane EM, Jackson JL, Hoffman SL. Meta-analysis: convalescent blood products for Spanish influenza pneumonia: a future H5N1 treatment? Ann Intern Med 2006; 145: 599-609.

55. Mupapa K, Massamba M, Kibadi K, et al. Treatment of Ebola hemorrhagic fever with blood transfusions from convalescent patients. International Scientific and Technical Committee. J Infect Dis 1999; 179(Suppl 1): S18-23.

56. Feldmann H, Jones SM, Daddario-DiCaprio KM, et al. Effective post-exposure treatment of Ebola infection. PLoS Pathog 2007; 3: e2.

57. Geisbert TW, Daddario-DiCaprio KM, Williams KJ, et al. Recombinant vesicular stomatitis virus vector mediates postexposure protection against Sudan Ebola hemorrhagic fever in nonhuman primates. J Virol 2008; 82: 5664-8.

58. Bukreyev A, Rollin PE, Tate $M K$, et al. Successful topical respiratory tract immunization of primates against Ebola virus. J Virol 2007; 81: 6379-88.

59. Geisbert TW, Daddario-Dicaprio KM, Lewis MG, et al. Vesicular stomatitis virus-based ebola vaccine is well-tolerated and protects immunocompromised nonhuman primates. PLoS Pathog 2008; 4: e1000225.

60. Jones SM, Feldmann H, Stroher $U$, et al. Live attenuated recombinant vaccine protects nonhuman primates against Ebola and Marburg viruses. Nat Med 2005; 11: 786-90. 